Darcy, S., \& Dickson, T. (2009). A Whole-of-Life Approach to Tourism: The Case for Accessible Tourism Experiences. Journal of Hospitality and Tourism Management, 16(1), 32-44.

\title{
A Whole-of-Life Approach to Tourism: The Case for Accessible Tourism Experiences
}

\begin{abstract}
This paper examines the concept of a whole-of-life approach to tourism through presenting the case for "accessible tourism". The importance of this approach is that it has been estimated that $30 \%$ of a population will have access requirements at some stage during their life. This paper presents the case for proactively developing a strategic accessible tourism approach by presenting a brief background to the area by firstly outlining the relationship between access, disability, ageing and tourism. Secondly, it reviews the development of easy access markets and accessible tourism, and places these in context to universal design. Thirdly, the paper overviews pertinent legislation that shapes the accessible tourism environment in Australia. Fourthly, accessible environments are placed within context to destination management and accessible destination experiences. The paper concludes by presenting four contemporary Australian examples of accessible destination experiences within broader destination management approaches.
\end{abstract}

Keywords: accessible tourism; disability; ageing; destination management; wholeof-life; universal design; 


\section{A Whole-Of-Life Approach to Tourism: The Case for Accessible Tourism Experiences}

You might not have noticed but there has been rejoicing in the streets as the Australian government became a signatory to the United Nations' (2006, 2008) Convention for the Rights of People with Disabilities. What is all the hype about the UN Convention for the Rights of People with Disabilities? What does this mean for the tourism industry? Do people with disabilities really travel anyway? Isn't it their responsibility to take care of themselves? Why are families with young children in prams, baby boomers and seniors linked to people with disabilities?

These and many other questions are commonly asked when discussing the concept of accessible tourism. Accessible tourism, as presented here, is about a life span or whole-of-life approach to tourism (Preiser \& Ostroff, 2001; Priestley, 2001). Just about everyone at some stage in their lives will have access requirements - whether that is personally acquired permanently or temporarily as a result of an accident or injury or through knowing family or friends with access requirements or with someone with whom they are travelling. A solution to meet people's access requirements for the travel and tourism industry and destination management is through the application of universal design principles, whereby providing access for all. As Figure 1 shows, it has been estimated that around $30 \%$ of the population have access requirements (Dickson, 2007).

\section{Figure 1: Universal design beneficiaries and proportion of Australians}

Understanding disability as part of human lifespan (Laplante, 1991; Quinn, 1998) has been part of research and policy for many decades. More recently, the Australian Commonwealth government has adopted whole-of-life and whole of government approaches (Commonwealth Attorney General's Dept,. 2009) to disability with a great deal of the momentum of these approaches developed in the employment and education sectors (Bagshaw, 2003). The approach recognizes the complexity of disability and that disability can occur at any stage of life whether it is in a temporary or permanent capacity. While disability can have dramatic consequences for the 
individual and their significant others', disability should not by nature reduce an individual's participation in the community in any area of their choosing. In line with the UN Convention on the Rights of People with Disabilities, the concept of citizenship (Hutchinson, 1997; Meekosha \& Dowse, 1997) is synonymous with the whole-of-life approach where rights to participation in the arts, leisure, sport and tourism are central to any notions of citizenship (Darcy, 2003; Darcy and Taylor, 2009). With this introduction, the paper presents a case for proactively developing a strategic approach to accessible tourism to facilitate the citizenship of those with access considerations through a whole-of-life approach. The paper does so by firstly providing a brief background to the area by outlining the relationship between access, disability, ageing and tourism. Secondly, it reviews the development of easy access markets and accessible tourism, and places these in context to universal design. Thirdly, the paper overviews pertinent legislation that shapes the accessible tourism environment. Fourthly, accessible environments are placed within context to destination management and accessible destination experiences. Last, the paper presents a short review of four contemporary approaches to accessible destination experience development.

\section{Defining Accessible Tourism: Why are families with children in prams, baby boomers and seniors are linked to people with disabilities?}

As will be demonstrated in the next section, the relationship between disability and ageing is undoubted and presents a challenge for the global tourism industry (WHO, 2007a). This has been recognised in Europe and America and the tourism industry has been seeking ways to ensure that its infrastructure and products are accessible. Design, planning and service operation can benefit from the principles of universal design that address the Easy Access Market (EAM) (Tourism New South Wales, 2005). As Tourism New South Wales identifies EAM as:

Any segment within the tourism market that prefers accessing tourism experiences with ease. This may include seniors who may prefer walking up a gentle ramp rather than tackling a large number of stairs. People with a disability, including those with physical and sensory disabilities, will find it easier to access tourism facilities where there is a continuous pathway and 
actile surfaces and clear signage (Tourism New South Wales, 2005).

Effectively, the majority of people will benefit from these provisions including our ageing population, parents with young children and who use prams, and employees as it incorporates good design for a range of occupational health and safety requirements (Darcy, 1998; Preiser \& Ostroff, 2001). Many developed nations have building codes and standards for access planning that operationalise these ideas. Within the Australian context, the concept of a continuous pathway is the foundation for the Australian Standard AS1428 for access and mobility, which is defined as

... an uninterrupted path of travel to or within a building providing access to all required facilities. Note: For non-ambulatory people, this accessible path does not incorporate any step, stairwell or turnstile, revolving door, escalator or other impediment which would prevent it being negotiated by people with a disability (Standards Australia, 2001, p. 8).

What then does this mean for the tourism industry? With the world economic crisis requiring a recasting of growth expectations for visitor numbers to Australia, the longterm outlook is that visitor numbers from overseas will double by the year 2017 and beyond, and the economic crisis may have a positive outcome for the domestic tourism market that had been flat for the last decade (Tourism Forecasting Committee, 2008). Amongst these people will be an increasing number of people with disabilities and people who are ageing.

Do people with access requirements travel? The greying of the population is both a Western and Asian phenomenon and many of our most lucrative international markets are drawn from countries experiencing an ageing of the population. Yet, unlike past generations of older people, this generation of baby boomers is seeking active, fulfilling and adventurous experiences for their post work lives (Hilt \& Lipschultz, 2005; Mackay, 1997; McDougall, 1998; Moschis, 2000; Muller \& Cleaver, 2000)(Salt, 2003). Tourism is seen as an important component of this quest for life experiences. The acknowledgement that people with access requirements do in fact want to travel is reflected in the tourism industry and government planning to 
incorporate their needs (Commonwealth Department of Industry Tourism and Resources, 2003; Tourism Australia, 2005a; Tourism New South Wales, 2005).

At a Commonwealth level the Commonwealth Department of Industry, Tourism and Resources (2003) has identified people with disabilities and seniors as an emerging market area and Tourism Australia (2005b) has established accessible tourism as a niche experience. However, to this point in time, there has not been a research, or industry, strategy developed to realise the opportunity that these groups offer. Yet, accessible tourism is not defined in any of the government documents. A 2005 Sustainable Tourism Cooperative Research Centre (STCRC) funded workshop was held to develop an agenda for accessible tourism. The Workshop provided an opportunity to bring together the stakeholders to collaboratively develop a research agenda for accessible tourism. The workshop proposed a working definition for accessible tourism as,

...a process of enabling people with disabilities and seniors to function independently and with equity and dignity through the delivery of universal tourism products, services and environments (adapted from OCA 1999). The definition is inclusive of the mobility, vision, hearing and cognitive dimensions of access (Darcy, 2006, p.4).

Importantly, this definition recognizes the importance of accessible tourism requiring a process grounded on the three important values:

- independence,

- equity, and

- dignity.

Where these three values are in place in a destination, as reflected in the design and experience development, people with access requirements will be able to travel more independently, thus requiring less support from tourism destinations, and at the same time be enabling them to enjoy the destination with equity and dignity. 
More recently Tourism New South Wales noted that 'Accessible tourism is about making it easy for all people to enjoy tourism experiences', which importantly places the focus on what anyone travels for - enjoyable tourism experiences. Yet, the process for ensuring this is far more complex than this statement belies. One way of understanding and developing a foundation for accessible tourism can be found through the concept of universal design. Universal design is a paradigm that extends the concepts of continuous pathways, access and mobility, and barrier-free environments to incorporate intergenerational and lifespan planning that recognises the nexus between ageing, disability and the continuum of ability of people over lifespan (Aslaksen, Bergh, Bringa, \& Heggem, 1997; Steinfeld \& Shea, 2001). Universal design has been defined as,

... the design of products and environments to be usable by all people, to the greatest extent possible, without the need for adaptation or specialised design...The intent of the universal design concept is to simplify life for everyone by making products, communications, and the built environment more usable by more people at little or no extra cost. The universal design concept targets all people of all ages, sizes and abilities (Center for Universal Design, 2003).

While it is not the purpose of this paper to examine the details of universal design principles, it is important to acknowledge the seven principles on which it is based and provide reference to documents for further understanding (Center for Universal Design, 2003, 2005; Preiser \& Ostroff, 2001). They are:

- Principle 1: Equitable Use

- Principle 2: Flexibility in Use

- Principle 3: Simple and Intuitive Use

- Principle 4: Perceptible Information

- Principle 5: Tolerance for Error

- Principle 6: Low Physical Effort

- Principle 7: Size and Space for Approach and Use (Center for Universal Design, 2003). 
The illustration of these principles in the Center for Universal Design provides a shift in understanding as to the benefits of the implementation for all industries. The implications of this interdisciplinary design approach are that access would become central to a design rather than an add-on for compliance reasons. Many groups would be the beneficiaries, for example, environments designed to be inclusive of mobility would be of assistance people using wheelchairs, those with mobility challenges, families with prams, travellers with heavy luggage, shoppers with trolleys and workers safely going about their duties. Signage and lighting would be informed by the needs of people with low vision, rather than just aesthetics as dictated by the tradition of architects and designers.

There has been a call for the tourism industry to adopt universal design principles as a foundation to achieving greater social sustainability (Rains, 2004) and as part of the triple bottom line business case for accessible tourism (Darcy, Cameron, Pegg, \& Packer, 2008). The Designing for the 21st Century III conference on universal design that had a stream on the travel and tourism industry ended with delegates proposing the Rio de Janeiro Declaration on Sustainable Social Development, Disability \& Ageing (Walsh, 2004). This declaration was important to link the principles of universal design with the social sustainability of the travel and tourism industry. Together with the previously mentioned WHO (2007), momentum has developed placing accessible tourism firmly on the global tourism agenda. Thus from a wholeof-life approach, the definition of accessible tourism may be expanded to,

Accessible tourism enables people with access requirements, including mobility, vision, hearing and cognitive dimensions of access, to function independently and with equity and dignity through the delivery of universally designed tourism products, services and environments. This definition is inclusive of all people including those travelling with children in prams, people with disabilities and seniors. 
In many countries, the framework for developing accessible tourism or implementing universal design can be found in disability discrimination law, building codes and accessibility standards (see later section). Yet, this is not a case for all countries particularly in the developing world. As a recent report identified in the Asia-Pacific only five of the 28 countries profiled had the combination of discrimination law and adequate building codes to ensure access and mobility (ESCAP, 2008). Without these requisite foundations to ensuring access and disability is firmly on the agenda across all levels of government and the private sector, even the most effective advocates can only achieve ad hoc outcomes rather than having a strategic approach to accessible tourism. The next section of the report reviews the potential market size and economic considerations that provide the business case, in addition to the social case, for developing such facilitating legislation and/or standards.

\section{Accessible Tourism: The Potential Market and Economic Contributions}

The Australian Bureau of Statistics (ABS) (2004) shows that substantial numbers of Australians have disabilities, and the level of disability in the community increased from 15 to 20 percent of the population from 1988-2003. At the same time, 17 percent of the population was aged over 60 years, of which 51 percent reported a disability (Australian Bureau of Statistics, 2004). As of June 2008, 1.4 million, or 6.4 percent, of the Australian population were aged 0-4 years (ABS 2008). Assuming half of these still use prams, results in 3 percent of the population. Together, the three groups of people: those aged 0-4 using prams, those aged over 60 years and all others who indicate they have a disability, account for an estimated 31 percent of the population may have access requirements. Further, the other beneficiaries of universal design include those with temporary disability and workers who are left with a much safer work environment. These groups were identified in Figure 1.

As Figure 2 shows, there is also a significant relationship between ageing and disability where a person is 14 times more likely to have a disability at age 65 than they are as a four-year-old (ABS 2004). Australia has an ageing population and the numbers and proportion of older people in Australia are growing dramatically (Commonwealth of Australia, 2002). This situation is largely reflected in all Western developed nations with a noticeable difference in Asian countries where ageing is 
occurring at a faster rate (Altman, 1975; World Health Organisation, 2007a). The World Health Organisation (WHO) has reflected considerations of ageing populations with the recent release of Global Age-friendly Cities: A Global Guide (2007a). The guide offers directions for urban planners to be more inclusive of the group, but also instils accountability through providing a checklist that older citizens can use to "monitor progress towards more age-friendly cities" (WHO, 2007b). Despite statistical evidence and advances in urban planning, there has been very little Australian research or policy that has sought to systematically engage with whole-oflife approaches to access considerations and tourism (Darcy, 2005).

\section{Figure 2: Disability rates by age and sex}

Globally there are over 650 million people with disabilities (Fujiura \& Rutkowskikmitta, 2001; Mercer \& MacDonald, 2007), equating to about $10 \%$ of humanity. Of the 20 percent or four million Australians with a disability - 520,000 have a mobility disability, 480,000 are blind or vision impaired, and 1 million are deaf or hearing impaired (ABS, 2003). As WHO (2007a) state, by 2020 there will be 1.2 billion people over 60 years of age. The 'greying' of the population has been well documented by the ABS, identified by Tourism Research Australia as a market opportunity (Tourism Australia, 2005c) and is a phenomenon that affects all of our major inbound markets. As Figure 3 presents, there are already significant numbers of people with disabilities identified in countries where disability statistics have been collected. These trends have considerable implications for global tourism (Dwyer, 2005).

\section{Figure 3: International population estimates of people with disabilities}

A number of the seminal studies first drew attention to the market potential of the group the US, UK and Canada through using national secondary data sources and extrapolating the market potential of the group (Keroul, 1995; Reedy, 1993; Touche Ross, 1993). This work was then extended by Australian, US, German and European researchers to estimate the value of accessible tourism within their localities by 
researching travel patterns and using gross demand estimates based on the population estimates of disability within communities. These included:

- Australia - \$A1.3 billion (Darcy, 1998);

- US - $\quad$ \$US13 billion (HarrisInteractive Market Research, 2005);

- Germany - €2.5 billion (Neumann \& Reuber, 2004); and

- Europe - $\quad € 80$ billion (Buhalis, Michopoulou, Eichhorn, \& Miller, 2005).

From an inbound perspective, it has been estimated that $7-8 \%$ of international travellers have a disability and it is this group who directly contribute to increased Gross Domestic Product (GDP) to the economy (Dwyer \& Darcy, 2008; HarrisInteractive Market Research, 2005). While these studies used the best available data for their time, economists had questioned the validity and reliability of gross demand estimates (Dwyer, Forsyth, \& Spurr, 2004). Through the Sustainable Tourism Cooperative Research Centre an opportunity arose to draw on or sophisticated approaches utilising the Tourism Satellite Accounts (Dwyer, Deery, Jago, Spurr, \& Fredline, 2007) to bring about a more reliable estimate of the economic contribution of accessible tourism together with other major national secondary data sources of the Disability, Ageing and Carers Survey (Australian Bureau of Statistics, 2004) and the National Visitor Survey (Bureau of Tourism Research, 2003). The other contribution of this work was to estimate the latent demand that could be further developed through a more considered approach to accessible tourism (Dwyer \& Darcy, 2008). This work estimates that the economic contribution of domestic overnight accessible tourism is $\mathrm{A} \$ 4.8 \mathrm{bn}$ or approximately 11 percent of the current market. Yet, the potential domestic overnight accessible tourism market was estimated to be worth A $\$ 8.7 b n$ or potential latent demand of A $\$ 3.9 b n$ (Dwyer \& Darcy, 2008). These figures do not incorporate the inbound potential as no valid and reliable research is available to estimate the contribution of this segment.

\section{Facilitating Legislation and the UN Convention}

To achieve the potential economic contribution from accessible tourism as discussed previously requires the implementation and application of the UN Convention as well as relevant national legislation and standards. Article 30 of the United Nations' (2006, 
2008) Convention for the Rights of People with Disabilities specifically identifies the rights of people with disabilities to culture, recreation and tourism. The Convention is the international framework under which nations implement human rights for people with disabilities. In Australia, the Disability Discrimination Act, 1992 (DDA) has been the way that the Australian Commonwealth government implements disability rights since $1^{\text {st }}$ January 1993 . The tourism sector has been the focus of the three major strategies of the DDA: education; legal redress through complaint cases and Federal court actions; and strategic planning. While human rights frameworks and legal obligations are one way of approaching and understanding disability, another way is to understand the nature of disability, its relationship to ageing and the conjunction of these two demographic phenomena as a distinct market segment - accessible tourism.

In an Australian context, the process for developing accessible tourism is facilitated by the disability discrimination and built environment legislation. The introduction of the Disability Discrimination Act, 1992 [Comm] (DDA) ensured that there are legal controls against discrimination on the grounds of disability. The spirit and intent of the DDA is further reinforced through existing and complementary State legislation and strategies. Provisions for mobility, vision, hearing and cognitive access are complemented through each state's environmental planning and development legislation. Each state's planning process makes reference to the Building Codes of Australia (Australian Building Codes Board, 1996) and this in turn calls upon Australian Standards for Access and Mobility (Standards Australia, 1992, 1993, 1999, 2001). Under the DDA, two disability standards had a significant impact on tourism. The first is the Disability Standard for Accessible Public Transport (Commonwealth Attorney General's Dept., 2005) that stipulates the levels of accessibility for public transport. This includes air travel, bus, rail, taxi and paratransit services but excludes charter operations. The second is more recent where the Australian Building Codes Board (2004) has entered into a process with the Commonwealth Attorney General's Dept. and the Human Rights and Equal Opportunity Commission (2004) (HREOC) to harmonise the DDA with the Australian Building Codes through the development of a draft Disability Standard for Access to Premises (Commonwealth Attorney General's Dept., 2004). The draft standards were at an impasse from 2004-2008 but have recently been released with a bill to go before Parliament in 2009 (Commonwealth 
Attorney General's Dept., 2008). A significant area of discussion is the accessibility of class three buildings, which constitute tourism accommodation. The standards for both transport and access to premises are rich areas of research.

The DDA is not retrospective legislation and has significant clauses for 'unjustifiable hardship' (Darcy, 2002; Handley, 2001). The DDA is implicitly directed to ensuring access to new environments (buildings, common domain, virtual environments, services, experiences etc.) and improving access to older environments where substantial redevelopment is occurring. The tourism industry should welcome an understanding of universal design and the DDA to ensure the social sustainability of the development is well placed to position Australian tourism for global demographic trends. Once these are in place then the opportunity for accessible destination experiences are far more likely.

The outcome of enabling environments should empower people with access requirements to make informed decisions about whether accessible destination experiences are appropriate for their needs. This short overview of the disability discrimination and built environment legislation frames the process for developing accessible tourism. Further, this research can take direction from the city accessibility, disability studies and the geographies of disability literature and research to incorporate the empowerment of people with disabilities within all environments. To do so, direction was taken from best practice in:

- city accessibility pedestrianisation and wayfinding principles create more accessible and environments (Aslaksen et al., 1997; Gleeson, 2001; Goldsmith \& PRP Architects (Firm), 2000; and Hall \& Imrie, 2001; Imrie, 1996; Sawyer \& Bright, 2004);

- disability studies and the geographies of disability where the role of space and place is interrogated from a disability perspective (Abberley, 1987; Oliver, 1990, 1996; Chouinard, 1997; Chouinard \& Grant, 1995; Cormode, 1997; Crouch, 2000; Golledge, 1996; Hahn, 1986; Imrie, 1996, 2000; Kitchin, 1998, 2000a; Wilton, 1999); 
- historic building accessibility where dynamic reuse has been championed by architects and planners who regard heritage as an evolving consideration over time (Goodall, Pottinger, Dixon, \& Russell, 2005; Goodall \& Zone, 2006; HREOC, 2007b; Martin, 1999);

- outdoor environments where the concepts of the recreation opportunity spectrum and challenge by choice question notions of what had been regarded as accessible outdoor environments (Environment Canada Parks Service, 1993; Griffin Dolon, 2000; Sport and Recreation Victoria, 1997; U.S. Architectural and Transportation Barriers and Compliance Board (Access Board), 2005); and

- information provision and website design where alternative format provision and W3C international protocols for website accessibility place the responsibility for such provision with organisations (Cameron, Darcy, \& Foggin, 2003; Human Rights and Equal Opportunity Commission, 2002; Shi, 2006; Williams, 2004).

In the Australian context, the Physical Disability Council of NSW (2007) (PDCN) inherently understands the socio-spatial elements discussed by this body of literature which they articulate through the concept of citizenship. Citizenship is the relationship between the built and outdoor environments, transport, employment, attendant care, equipment, leisure and tourism that are at the "core of what it is to be human' (Hutchison, 1997). Both PDCN and Hutchinson (1997) recognise that citizenship rights can only be expressed when people with disabilities have access to all components of social participation. This involves employment, public transport, the built environment and psychological manifestations of access to produce functioning social spaces. They recognise that powerful social institutions must be changed to be inclusive of disability within their organisational cultures.

Tourism is a right of citizenship and tourism institutions need to be inclusive of people with disabilities, and seniors, as part of the accessible tourism market. The application of legislation is one means, but possibly the most straight forward would be where there is a change of perspective or behaviour of tourism developers and entrepreneurs who see the market potential and apply universal design principles, 
regardless of legislative or planning requirements. The challenge in a context such as Australia is that the three tiers of Government need to be engaged to ensure an integrated and coherent legislative and policy response across areas such as disability discrimination, active ageing, human rights, building codes, urban design and planning approvals. The recently released Draft Disability Standards for Access to Premises (Commonwealth Attorney General's Dept. 2008) offer the potential to achieve some aspects of this challenge. The outdoor environment is more challenging but people with disabilities have shown that when provided the opportunity to challenge and interact with all types of outdoor environments, they are willing to accept the challenge with the understanding of its inherent risk (see http://www.dability.org/).

\section{Destination Management Approach}

The earlier elements in this article need to be incorporated within the tourism planning approach of the local and state governments in Australia. This is due to the Federal approach to government, the Australia Constitution Act, 1901, which leaves responsibility for environmental planning control largely at these levels of government. Most state tourism organisations in some form apply a stakeholder-based destination management approach (Dredge \& Jenkins, 2003), where in Tourism New South Wales' case they assume responsibility for: Planning - policy formulation, management of infrastructure, resources and development; Promotion - promotional marketing of destinations; and Coordination - coordination of government agencies (both horizontally and vertically) that have control of tourism resources, for example, agencies for air transport $(2002,2008)$.

These responsibilities seek to balance the interests and responsibilities of various stakeholders: (1) host population, (2) business community, (3) the government, and (4) visitors. It is understood that the broad direction is for tourism to have an increased contribution to sustainable development through effective partnerships and quality visitor experiences through building sustainable destinations. From a global perspective, Ritchie and Crouch's (2003, p. 63) Model of Destination Competitiveness \& Sustainability is widely recognised by tourism researchers and the WTO. Ritchie, 
Crouch and Hudson (2001) propose that the measure of a tourism destinations competitiveness and sustainability is a blend of two dimensions:

the actual success of the destination as measured by the contribution which tourism makes to enhancing the sustainable well-being of destination residents; plus the extent to which the foregoing level of success has been achieved through an effective deployment of destination resources (Ritchie, Crouch, \& Hudson, 2001, p. 4)

Thus, a destination that is accessible for tourists will also be accessible for residents, with commensurate benefits in social engagement, health outcomes and economic benefits (WHO, 2007a).

Ritchie, Crouch and Hudson (2001) set out five sets of factors that contribute to destination's competitiveness and sustainability:

1. Core resources and attractors - factors motivating tourists to visit;

2. Supporting factors and resources - those characteristics that support the development of the tourist industry;

3. Destination management - activities carried out to support and maximise outcomes for the four other factors of the model; and

4. Destination policy, planning and development - creation of an environment where sustainable tourism can flourish;

5. Qualifying and amplifying determinants - defining of the scale, limit or potential of the destinations competitive capacity, which are beyond the control of the tourism sector (Ritchie \& Crouch, 2003).

The five sets of factors can be readily applied to an accessible tourism context. Accessible tourism essentially replicates 'core resources and attractors' and the extent to which the four remaining factors incorporate the principles of independence, equity and dignity within destination management approaches will impact on the realisation of accessible destination experiences. To date only Israeli (2002), Ernawati \& Sugiarti (2005) and Darcy and Small (2008) have examined precinct and destination 
management approaches to accessible tourism.

\section{Accessible Destination Experiences}

Yet, the provision of accessible destinations does not guarantee accessible destination experiences for people with disabilities given that each leisure or tourism experience is 'the subjective mental state felt by participants' (Otto \& Ritchie, 1996, p. 166) which will be, in part, impacted by the dimensions of access. As Hayllar and Griffin's (2005) work on the essence of experiencing urban tourism precincts suggests, tourists seek out experiences that provide them with a 'sense of place'. Sense of place has been used in a tourism context synonymously with authenticity to capture what can be regarded as quintessential to a destination (Lew, 1989). The accessible tourism market is no different in that they want to experience what is quintessential to the destination but require a street-smart approach to the accessibility of the destination to achieve this outcome. A great deal of disability research has rightly focused on the barriers and constraints to experiences of people with disabilities but this work seeks to identify what accessible destination experiences are possible with the provision of information on which it would disabilities can make informed decisions about the accessibility for their needs. In much the same way as Wang (1999) argues that authenticity within tourism is a multifaceted construct, to experience accessible destination experiences requires an understanding that the experience itself is multifaceted based on a person's access considerations whether they are: mobility; vision; hearing; cognitive; and others.

With reference to the earlier discussion regarding 'Disability Access and Built Environment Legislation', to realise quintessential experiences within accessible tourism, tourism organisations need to consider more than simply physical access requirements, which has been the focus of much of the debate regarding street scape, transport and accommodation. Development and provision of accessible destination experiences should be underpinned by a an experiential approach to understanding what any tourists would regard as a quintessential experience, and developing processes for integrating of the enablers and facilitators of accessibility within the understanding of these experiences. Accessible destination experiences can be defined as: 
Accessible destination experiences take direction from universal design principles to offer independent, dignified and equitable quintessential experiences that provide a 'sense of place' within the destination region for people with access requirements (Darcy, Cameron, Dwyer et al., 2008, p. 51).

The significance of the "sense of place" is that there is a responsibility placed with the experience creators to act as enablers and facilitators of accessible experience. Implications for the tourism context are that a series of infrastructure and enablers must be put in place by destination managers for tourists with disabilities to immerse themselves in the accessible destination experience. For the most part, however, these enablers are not provided for people with disabilities through access provisions. Instead, there is no responsibility taken by government or the tourism industry to develop knowledge management that integrates the needs of people with disabilities within mainstream product development, information provision or electronic distribution systems. Tourists with disabilities are left to make sense of a destination for themselves. The result, as documented by numerous studies (see Darcy 2006), is that people with disabilities are left to discover their own path and to create their own experiences with the inadequate information systems provided by government and the tourism industry. While Tourism Australia (2005a) has targeted experience seekers and identified accessible tourism as a niche experience since the White Paper (2003), little has been done to facilitate the development of these experiences in comparison to other market segments. The development of accessible destination experiences as the foundation for accessible tourism seems a logical step.

\section{Australian and Overseas Approaches to Accessible Destination Experiences}

As with the Australian responses, a great deal of overseas research, approaches and government responses to accessible tourism have focused on the 'mechanics' of access through infrastructure with little emphasis on the facilitation of the destination experience. This has included access to attractions, hotel rooms, air travel, paratransit, day tours, hospitality provision, leisure activities, and travel agents. The best recent examples of these approaches is Europe for All (Europe for All, 2007) and the 
European Network for Accessible Tourism (European Network for Accessible Tourism, 2007) (ENAT), which are both acting in coordinating, facilitating, marketing, branding and educative roles to encourage industry and national responses to accessible tourism across Europe. These organisations are the product of Tourism for All in Europe that has been operating since 1990. The program has been coordinated by the European Commission that also provided significant funding, which resulted in a great deal of policy and research to rationalise the outcomes across the European Union countries. The approach is an example of best practice for other cooperative national tourism bodies (e.g. ASEAN) and national tourism organisations.

The Setting a Research Agenda for Accessible Tourism (Darcy, 2006) identified the importance of providing accessible tourism experiences that reflect destination experiences that the rest of the community seek. In an Australian context, a series of guides provided 'listings' of 'accessible" hotels and attractions but only one access guide offered direction for developing 'a sense of place' to destination areas. Cameron (1995; 2000) provided a sound foundation to access infrastructure that people base destination choice on and went further to present key experiences that are at the foundation of the destination experiences for the regions. He did so by integrating key access considerations within a 'Lonely Planet' or 'Rough Guide' style, both of which he has written for. People that have used these guides suggest that they are successful because tourists do not have to do all of the intricate planning and research themselves, and they are that confident in the reliability of the information, that they do not have to think about access and can concentrate on their holiday experiences.

Four current projects have sought to adopt the principles suggested by these approaches. As suggested by Darcy (2006) the approaches follow a broad hierarchy of accessible tourism involving: accessible touring routes, day trips, precinct areas and individual attractions. Given the contemporary and developing nature of these projects, it will be some time before any evaluation or review may be conducted to determine their impact and effectiveness. It has been proposed that this will be followed up in a subsequent paper. The projects are: 


\section{Tourism Australia \& Easy Access Australia- Accessible Touring Routes and Daytrip Guides}

Tourism Australia recognized the potential of these approaches and engaged Bruce Cameron, Easy Access Australia to prepare 10 Accessible touring Routes and five accessible day trip planners from the Sydney, Melbourne, Brisbane, Perth and Adelaide (Tourism Australia \& Bruce Cameron Easy Access Australia, 2008). This project is to be commended for its national approach and is the result of a collaborative the accessible tourism working group between tourism Australia and the state tourism organisations led by Jacqui Tully (Tourism Australia, 2008). Not surprisingly, the documents do not provide very much detail on the underlying infrastructure or enablers but provide an excellent insight into the 'sense of place'.

\section{Western Australian Disability Services Commission and Local Government - You're Welcome program.}

Two Western Australian initiatives focused on local government areas incorporate many elements that provide an excellent foundation for visitors to areas - Guestability (Harrop, 2004) and You're Welcome (City of Perth, 2007). First, Guestability is a program initiated by the Independent Living Centre in conjunction with the Disability Services Commission to educate the industry to understand the needs of people with disabilities. Second, You're Welcome is a website that identifies Clusters in Perth shown in Figure 4, and provides an examination of access features and suggests must see attractions. This initiative is set to expand to every local government area in Western Australia. Lastly, both initiatives incorporate resources for industry but neglect to promote the excellent tourism and hospitality disability awareness training package You can make a difference to customer service for people with disabilities (Disability Services Commission (WA), 2000).

\section{Figure 4: $\quad$ City of Perth 'Clusters'}




\section{Alpine Accessible Tourism Project}

The Alpine Accessible Tourism Project was funded under Ausindustry's Australian Tourism Development Program and was co-ordinated by Disabled WinterSport Australia (DWA). It sought to build upon DWA's 30 years of experience of providing snow sport experiences for people with disabilities to develop summer accessible tourism opportunities. The project involved:

- assessing over 100 tourism providers and preparing reports outlining the accessibility of their products (this was based upon previous work by Bruce Cameron and Simon Darcy), these reports could be hosted on their websites;

- developing a web-based toolkit for tourism operators who wished to develop their levels of accessibility;

- providing training to outdoor activity operators to aid them in being more inclusive in their activities; producing Mobility maps of alpine communities in New South Wales and Victoria;

- writing short break stories that could be submitted to a range of journals, newspapers and other marketing bodies to promote those businesses that had been assessed (Dickson \& Hurrell, 2008).

Figure 5 is a photo from the launch that culminated in a hike up Mt Kosciuszko to celebrate the completion of the project on the International Day for People with Disabilities in 2008. Participants included representatives of all access groups, including five people using wheelchairs, one person with a guide dog, a mother with two children in a cycle trailer and several older people. The hike was by no means easily accessible with the gradients and surface not compliant to AS1428 but in the spirit of adventure tourism the participants with access considerations accepted the challenge and the inherent risk involved.

\section{Figure 5 Summit of Mt Kosciuszko}

\section{Sydney for All}

Figure 6 presents the front page of Sydney for All Web portal, which was the outcome of the research project that sought to collaboratively promote accessible destination experiences within the Sydney CBD. The Web portal brand was 
developed by the industry partners of Tourism NSW, the Tourism and Transport Forum, NSW Dept of Environment and Climate Change. The research project was developed through participatory action research with the major stakeholders, tourism attractions and identified 18 destination experiences within the Sydney CBD and surrounding environments of the Rocks, Royal Botanic Gardens and the Sydney Harbour National Park. The accessible destination experiences were a combination of commercial providers, the not-for-profit sector and government cultural institutions. The accessible destination experiences were supplemented with enabling information on transport, parking, toilets and wayfinding systems. The Web portal complies with the highest web accessibility standards - W3C - as evidenced through the rigorous compliance testing and the project winning a Vision Australia 2009 Making a Difference Award. The Web portal recently completed a four-month trial where it was evaluated through built-in consumer-based evaluation research module and Google analytics. Over half the hits on the site were from Australia's major inbound markets. The portal is a starting point to understanding accessible tourism through focusing on universal design, destination experience and management frameworks rather than using constraints based approaches that dominate mainstream access auditing (see Darcy et al. 2008).

\section{Figure 6: Web Portal Front Page http://www.sydneyforall.com/}

\section{Conclusion}

The paper has highlighted how a whole-of-life perspective can meet tourism demand of the future through understanding the nexus between disability and ageing. This has been achieved through providing a definition of accessible tourism that is inclusive of all dimensions of access; providing an overview of the accessible tourism market; discussing the relationships between accessibility and the built environment; converting this knowledge into accessible destination experiences; integrating this within destination management processes; and presenting contemporary approaches to accessible destinations. The United Nations Convention on the Rights of People with Disabilities $(2006 ; 2008)$ has created a greater expectation that people with disabilities in all parts of the world should be able to access all the rights of citizenship. From a disability perspective, there is an expectation that the tourism 
industry should better plan, design, operate and provide accessible experiences for all people with access requirements. To do so requires an understanding of the importance to an individual of having their needs met through the operationalising of the principles universal design and the values of independence, equity, and dignity to create enabling accessible tourism destination experiences. The Commonwealth and state governments have recognised the market nexus between disability and ageing. However, as the White Paper suggests there is a need to create niche experiences that go beyond the building compliance and access audits. Developing accessible experiences based on a "sense of place" needs to be put in context of the destination management processes that integrate the overall information provision and marketing for a destination. A key driver for developing these accessible destination experiences will be the individual tourism enterprises that appreciate the business opportunity and who seek to create experiences that are accessible for all, and by nature, positioned to be more socially sustainable. For this to be successfully developed and implemented, the destination must then have knowledge management responses in place that present information in a way that allow individuals with access considerations to make informed decisions for their needs. 


\section{Acknowledgements}

The authors would like to acknowledge - to be included after the editorial process.

\section{References}

Altman, I. (1975). The Environment and Social Behavior. Monterey, California: Brooks-Cole Publishing Co.

Aslaksen, F., Bergh, S., Bringa, O. R., \& Heggem, E. K. (1997). Universal Design: Planning and Design for All. Oslo: The Norwegian State Council on Disability.

Australian Building Codes Board. (1996). Building Code of Australia. Canberra: CCH Australia.

Australian Building Codes Board. (2004). Draft Access Code for Buildings (Press release). Canberra: Australian Building Codes Board

Australian Bureau of Statistics. (2003). Disability, aging and carers, Australia: summary of findings (Catalogue No.4430.0) (AuStats No. Catalogue No.4430.0). Canberra: ABS

Australian Bureau of Statistics. (2004). Disability Ageing and Carers Summary Of Findings, 2003 (Cat No. 4430.0). Canberra: Australian Bureau of Statistics

Bagshaw, M. (2003, 27-28 February). People with Disabilities: a Whole of Life Approach. Paper presented at the Making Connections: NSW Premier's Forum on Spinal Cord Injury and Conditions, Sydney Exhibition \& Convention Centre, Sydney.

Bennett, R., \& McColl-Kennedy, J. R. (2003). Services marketing: a managerial approach. Milton, Queensland: Wiley.

Buhalis, D., Michopoulou, E., Eichhorn, V., \& Miller, G. (2005). Accessibility market and stakeholder analysis - One-Stop-Shop for Accessible Tourism in Europe (OSSATE). Surrey, United Kingdom: University of Surrey

Bureau of Tourism Research. (2003). National visitor survey: travel by Australians data set. Canberra: Bureau of Tourism Research.

Cameron, B. (2000). Easy Access Australia (2nd ed.). Kew, Vic: Kew Publishing.

Cameron, B., Darcy, S., \& Foggin, S. E. A. (2003). Barrier-Free Tourism for People with Disabilities in the Asian and Pacific Region (No. ST/ESCAP/2316). New York: UN ESCAP

Center for Universal Design. (2003). Universal Design Principles. Retrieved 2 May, 2003, from www.design.ncsu.edu:8120/cud/

Center for Universal Design. (2005). Environments and Products for All People. Retrieved 7 October, 2005, from http://www.design.ncsu.edu/cud/

City of Perth. (2007). You're Welcome - WA Access Initiative. Retrieved 18 Jan, 2008, from http://www.perth.wa.gov.au/WAAccess/vis13_waaccess.html

Commonwealth Attorney General's Dept. (2004). Draft Disability Standards for Access to Premises (Buildings) 200X. Canberra: AGPS.

Commonwealth Attorney General's Dept. (2005). Disability Standards for Accessible Public Transport. Retrieved 1 Sept, 2005, from http://www.ag.gov.au/agd/WWW/agdHome.nsf/Page/Department_Civil_Justi ce_and_Legal_Services_Group_Information_Law_and_Human_Rights_Divisi 
on_Human_Rights_Branch_Human_Rights_Branch_Publications_Disability_ Standards_for_Accessible_Public_Transport

Commonwealth Attorney General's Dept. (2008). Disability (Access to Premises Buildings) Standards. Retrieved 2 December, 2008, from http://www.ag.gov.au/premisesstandards

Commonwealth Attorney General's Dept. (2009). Developing a National Disability Strategy for Australia: Access Inclusion Participation. Canberra: Commonwealth of Australia.

Commonwealth Department of Industry Tourism and Resources. (2003). Green paper: A Medium to Long Term Strategy for Tourism. Canberra: Department of Industry, Tourism and Resources

Commonwealth of Australia. (2002). Intergenerational Report 2002-03, Budget Paper No. 5. Canberra: AGPS

Darcy, S. (1998). Anxiety to access: tourism patterns and experiences of New South Wales people with a physical disability. Sydney: Tourism New South Wales

Darcy, S. (2002, 16-18 May). People with disabilities and tourism in Australia: a human rights analysis. Paper presented at the Tourism and Well Being - 2nd Tourism Industry and Education Symposium, Jyvaskyla, Finland.

Darcy, S. (2003, 5-8 February). Disabling journeys: The tourism patterns of people with impairments in Australia. Paper presented at the Riding the Wave of Tourism and Hospitality Research, CAUTHE - Southern Cross University, Lismore.

Darcy, S. (2003, 27-28 February). Disability, Community and Citizenship. Paper presented at the Making Connections: NSW Premier's Forum on Spinal Cord Injury and Conditions, Sydney Exhibition \& Convention Centre, Sydney.

Darcy, S. (2006). Setting a Research Agenda for Accessible Tourism. Sustainable Tourism for Cooperative Research Centre, Gold Coast. Retrieved May, from http://www.crctourism.com.au/BookShop/BookDetail.aspx?d=473

Darcy, S., Cameron, B., Dwyer, L., Taylor, T., Wong, E., \& Thomson, A. (2008). Technical Report 90064: Visitor accessibility in urban centres. Sustainable Tourism Cooperative Research Centre, Gold Coast. Retrieved July 2007, from http://www.crctourism.com.au/BookShop/BookDetail.aspx?d=626

Darcy, S., Cameron, B., Pegg, S., \& Packer, T. (2008). Technical Report 90042: Developing Business Cases for Accessible Tourism. Sustainable Tourism Cooperative Research Centre, Gold Coast. from http://www.crctourism.com.au/default.aspxg

Darcy, S., \& Small, J. (2008). Theorising Precincts: Disciplinary Perspectives. In B. Hayllar, T. Griffin \& D. Edwards (Eds.), City Spaces - Tourist Places: Urban Tourism Precincts (pp. 63-91). Elsevier: Oxford, UK.

Dickson, T. J. (2007). Accessible summer alpine tourism - quality barrier-free tourism. Canberra, ACT: Centre for Tourism Research, University of Canberra.

Dickson, T., \& Hurrell, M. (Writer) (2008). Alpine Accessibility Tourism Toolkit [DVD]. In T. Dickson (Producer). Australia: Australian Tourism Development Program/Australian Federal Government Initiative.

Disability Services Commission (WA). (2000). You can make a difference to customer service for people with disabilities [kit]: hospitality, tourism, retail \& entertainment industries. West Perth, W.A.: Disability Services Commission. 
Dredge, D., \& Jenkins, J. (2003). Destination place identity and regional tourism policy. Tourism Geographies, 5(4), 383-407.

Dwyer, L. (2005). Trends underpinning global tourism in the coming decade. In W. Theobald (Ed.), Global Tourism (pp. 529-545). Burlington, MA: Butterworth Heinemann.

Dwyer, L., \& Darcy, S. (2008). Chapter 4 - Economic contribution of disability to tourism in Australia. In S. Darcy, B. Cameron, L. Dwyer, T. Taylor, E. Wong \& A. Thomson (Eds.), Technical Report 90040: Visitor accessibility in urban centres (pp. 15-21). Gold Coast: Sustainable Tourism Cooperative Research Centre.

Dwyer, L., Deery, M., Jago, L., Spurr, R., \& Fredline, L. (2007). Adapting the Tourism Satellite Account Conceptual Framework to Measure the Economic Importance of the Meetings Industry. Tourism Analysis, 12(4), 247-255.

Dwyer, L., Forsyth, P., \& Spurr, R. (2004). Evaluating tourism's economic effects: new and old approaches. Tourism Management, 25(3), 307-317.

Ernawati, D., \& Sugiarti, R. (2005). Developing an accessible tourist destination model for people with disability in Indonesia. Tourism Recreation Research, 30(3), 103-106.

ESCAP. (2008). Disability at a glance: a Profile of 28 Countries and Areas in Asia and the Pacific. United Nations - Economic and Social Commission for Asia and the Pacific, Vietnam. from http://www.unescap.org/esid/psis/disability

Europe for All. (2007). Europe for All - Better information for discerning travellers. Retrieved 1 January, 2008, from http://www.europeforall.com/

European Network for Accessible Tourism. (2007). Working together to make Tourism Accessible for All in Europe. Retrieved 1 January, 2008, from http://www.accessibletourism.org/

Fujiura, G. L., \& Rutkowskikmitta, V. (2001). Counting Disability. In G. L. Albrecht, K. D. Seelman \& M. Bury (Eds.), Handbook of Disability Studies (pp. 69-96). Thousand Oaks, Calif: Sage Publications.

Handley, P. (2001). 'Caught Between a Rock and a Hard Place': Anti-discrimination legislation in the liberal state and the fate of the Australian Disability Discrimination Act. Australian Journal of Political Science, 36(3), 515-528.

HarrisInteractive Market Research. (2005). Research among adults with disabilities travel and hospitality. Chicago: Open Doors Organization

Harrop, A., O'Brien, A. (2004). Guestability: Signposts to accommodating people of all ages and abilities. Perth: Independent Living Centre of WA.

Hayllar, B., \& Griffin, T. (2005). The precinct experience: a phenomenological approach. Tourism Management, 26(4), 517-528.

Human Rights and Equal Opportunity Commission. (2002). World Wide Web Access: Disability Discrimination Act Advisory Notes. 3.1. Retrieved 5 January, 2007, from http://www.hreoc.gov.au/disability_rights/standards/www_3/www_3.html

Hutchison, P. (1997, 10-12 October). Citizenship - Setting the Scene (Keynote Address). Paper presented at the Citizenship...beyond Disability Conference, Brisbane.

Israeli, A. (2002). A Preliminary Investigation of the Importance of Site Accessibility Factors for Disabled Tourists. Journal of Travel Research, 41(1), 101-104.

Keroul. (1995). Tourism for People with Restricted Physical Ability. Quebec: Keroul.

Laplante, M. P. (1991). Disability in Basic Life Activities Across the Life Span.

Washington, DC 
Lew, A. A. (1989). Authenticity And Sense Of Place In The Tourism Development Experience Of Older Retail Districts. Journal of Travel Research, 27(4), 1522.

Meekosha, H., \& Dowse, L. (1997). Enabling Citizenship: Gender, disability and citizenship in Australia. Feminist Review, 57(Autumn), 49-72.

Mercer, S. W., \& MacDonald, R. (2007). Disability and human rights. The Lancet, 370(9587), 548-549.

Neumann, P., \& Reuber, P. (2004). Economic Impulses of Accessible Tourism for All (Vol. 526). Berlin: Study commissioned by the Federal Ministry of Economics and Technology \& Federal Ministry of Economic and Labour (BMWA).

Otto, J. E., \& Ritchie, J. R. B. (1996). The service experience in tourism. Tourism Management, 17(3), 165-174.

Physical Disability Council of NSW. (2007, 1999). Position Papers - Citizenship and Disability. from http://www.pdensw.org.au/publications/statements/index.html

Preiser, W., \& Ostroff, E. (2001). Universal Design Handbook. New York: McGrawHill.

Preiser, W. F. E., \& Ostroff, E. (2001). Universal Design Handbook. New York: McGraw-Hill.

Priestley, M. (2001). Disability and the Life Course: Global Perspectives: Cambridge University Press.

Quinn, P. (1998). Understanding disability: A lifespan approach. Thousand Oaks, CA: Sage.

Rains, S. (2004). Universal Design and the International Travel \& Hospitality Industry. Paper presented at the Designing for the 21st Century III, Rio de Janeiro, Brazil: 7th - 12th December, 2004.

Reedy, J. (1993). Marketing to consumers with disabilities: how to identify and meet the growing market needs of 43 million Americans. Chicago, Ill: Probus Pub Co.

Ritchie, B., \& Crouch, G. (2000). The competitive destination: a sustainability perspective. Tourism Management 21(1), 1-7.

Ritchie, B., Crouch, G., \& Hudson, S. (2001). Developing Operational Measures for the Components of a Destination Competitiveness / Sustainability Model: Consumer versus Managerial Perspectives. In J. Mazanec, G. Crouch, B. Ritchie \& A. Woodside (Eds.), Consumer Psychology of Tourism, Hospitality and Leisure (pp. 1-18). Wallingford, UK: CABI Publishing

Ritchie, B., \& Crouch, G. I. (2003). The Competitive Destination: A Sustainable Tourism Perspective: CABI Publishing.

Salt, B. (2003). The Big Shift: Welcome to the third Australian Culture. Sydney: Hardie Grant Books.

Shi, Y. (2006). The accessibility of Queensland visitor information centres' websites. Tourism Management, 27(5), 829-841.

Standards Australia. (2001). AS 1428.1 Design for access and mobility - General requirements for access - New building work. Homebush, NSW: Standards Australia.

Steinfeld, E., \& Shea, S. M. (2001). Fair Housing: Toward Universal Design in MultiFamily Housing. In W. F. E. Preiser \& E. Ostroff (Eds.), Universal Design Handbook (pp. 35.31-35.13). New York: McGraw-Hill.

Touche Ross. (1993). Profiting from Opportunities - A new market for tourism. London: Touche Ross \& Co. 
Tourism Australia. (2005a). The experience seeker. Tourism Research Centre, Sydney. from http://www.tourism.australia.com/content/aussie_experiences/2007/experience _seekers.pdf

Tourism Australia. (2005b). Markets - Australian experiences - niche experiences. Retrieved $20 \quad$ May, 2005, from http://www.tourism.australia.com/Markets.asp?lang=EN\&sub=0338

Tourism Australia. (2005c). Mature-Aged Travellers in Australia: Snapshot. Retrieved $26 \quad$ September, 2006, from http://www.tourism.australia.com/Research.asp?lang=EN\&sub=0361

Tourism Australia. (2008). Accessible tourism working group from State Tourism Organisations. Tourism Australia, Sydney. from http://www.tourism.australia.com/Marketing.asp?lang=EN\&sub=0437\&al=25 72

Tourism Australia, \& Bruce Cameron Easy Access Australia. (2008). Accessible Touring Routes and Daytrip Guides. Tourism Australia, Sydney. from http://www.tourism.australia.com/Marketing.asp?lang=EN\&sub=0437\&al=25 71

Tourism Forecasting Committee. (2008). Tourism Forecasting Committee 2008 Issue 1. Sydney: Tourism Research Australia

Tourism New South Wales. (2002). Towards 2020: New South Wales Tourism Masterplan, Including a three-year Action Plan: 2002/03 to 2004/05. Sydney: Tourism New South Wales.

Tourism New South Wales. (2005). Easy Access Markets. Retrieved 10 May, 2005, from http://corporate.tourism.nsw.gov.au/scripts/runisa.dll?CORPORATELIVE.65 632:2COLUMN:933237702:pc=EASYACCESS

Tourism New South Wales. (2008). Towards 2020: New South Wales Tourism Masterplan (Revised ed.). Sydney: Tourism New South Wales.

UN ESCAP. (2008). Disability at a glance: a Profile of 28 Countries and Areas in Asia and the Pacific. United Nations - Economic and Social Commission for Asia and the Pacific, Vietnam. from http://www.unescap.org/esid/psis/disability

United Nations. (2006). Convention on the Rights of Persons with Disabilities. New York http://www.un.org/esa/socdev/enable/rights/convtexte.htm: United Nations General Assembly A/61/611 - 6 December 2006.

United Nations. (2008, 3 May). Landmark UN treaty on rights of persons with disabilities enters into force. Retrieved 12 May, 2008, from http://www.un.org/esa/socdev/enable/rights/convtexte.htm http://www.un.org/apps/news/story.asp?NewsID=26554\&Cr=disab\&Cr1=

Walsh, C. J. (2004). Rio de Janeiro Declaration on Sustainable Social Development, Disability \& Ageing. Paper presented at the Designing for the 21st Century III - an international conference on universal design, Rio de Janeiro, Brazil: 7th 12th December, 2004.

Wang, N. (1999). Rethinking Authenticity in Tourism Experience. Annals of Tourism Research, 26(2), 349-370.

Williams, R., Rattray, R. \& Stork, A. (2004). Web site accessibility of German and UK tourism information sites. European Business Review, 16(6), 577-589. 
World Health Organisation. (2007a). Global Age-friendly Cities: A Guide. from http://www.who.int/ageing/publications/Global_age_friendly_cities_Guide_E nglish.pdf

World Health Organisation. (2007b). Media Release: New guide on building agefriendly cities, . accessed 26 October 2007 from http://www.who.int/mediacentre/news/releases/2007/pr53/en/index.html World Health Organisation,.

World Health Organization. (2007). Global Age-friendly Cities Guide from http://www.who.int/ageing/age_friendly_cities/en/index.html 
Figure 1: Universal design beneficiaries and proportion of Australians

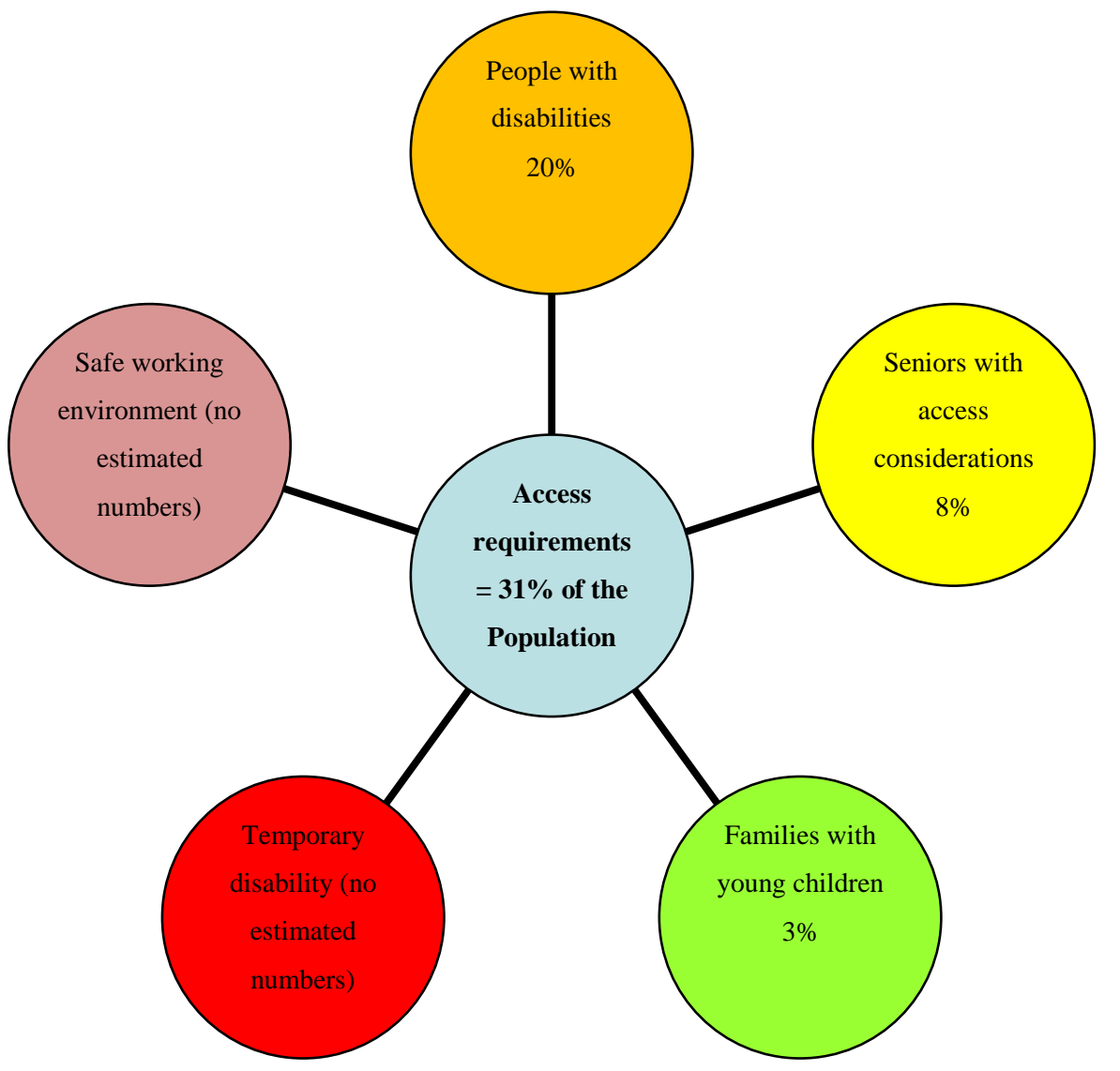

Source: Darcy and Dickson 2009 
Figure 2: Disability rates by age and gender over lifespan

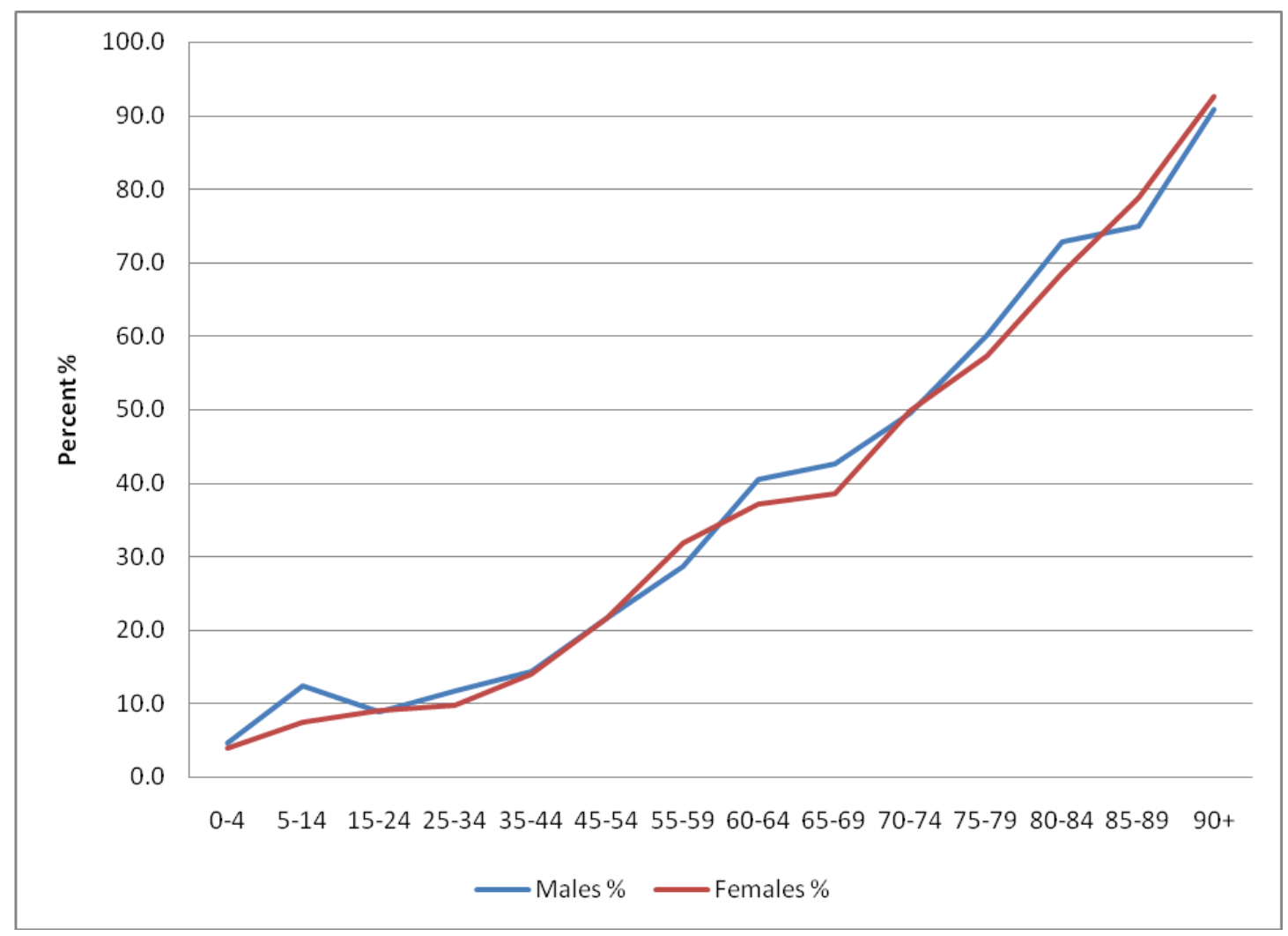

Source: ABS (2004, p.6) 
Figure 3: International population estimates of people with disabilities

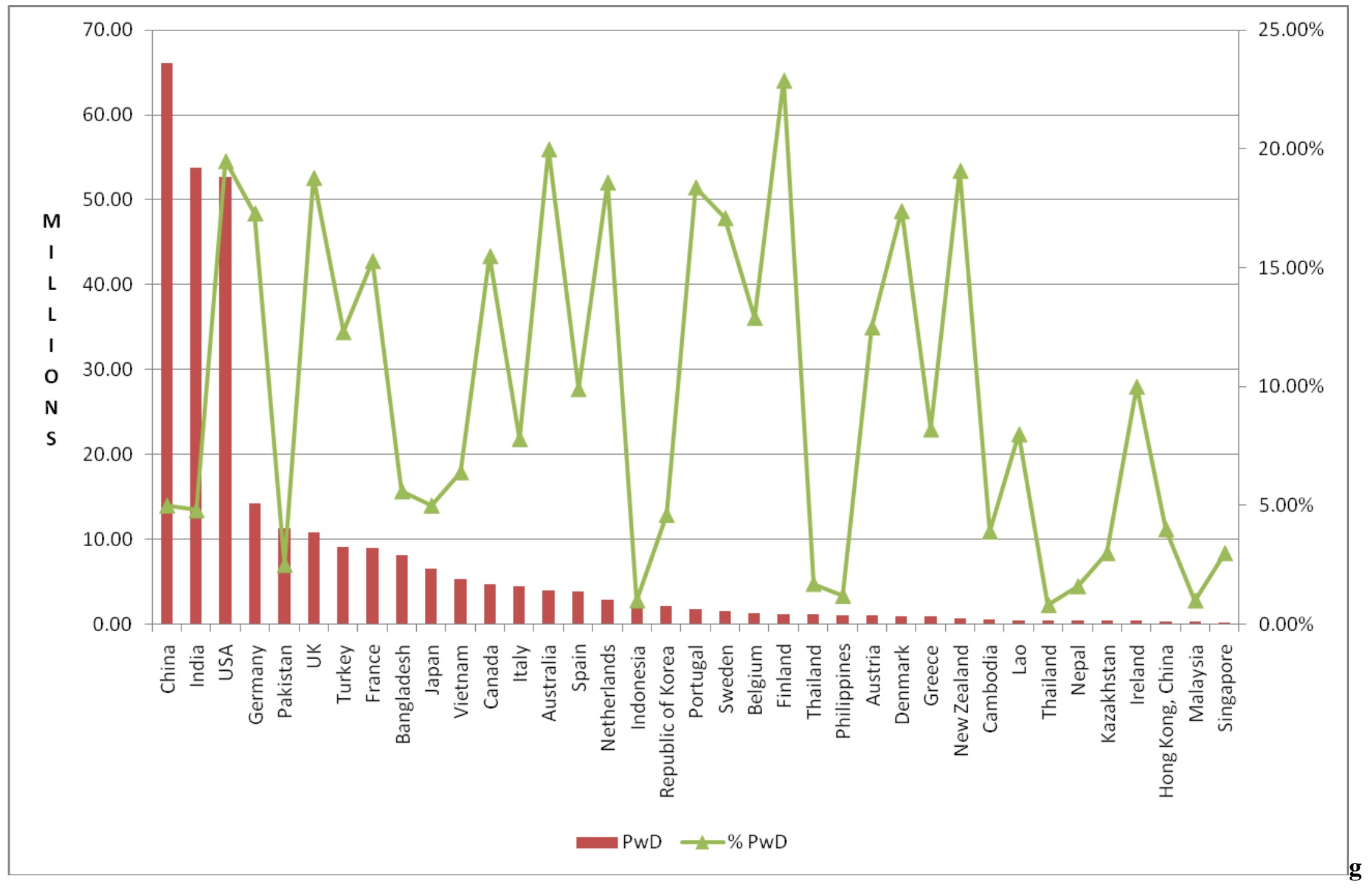


Source: UN ESCAP 2008; Eurostat research results (2003), cited in OSSATE Accessibility Market and Stakeholder Analysis (http://www.ossate.org/doc_resources/) 2005. 
Figure 4: City of Perth 'Clusters'

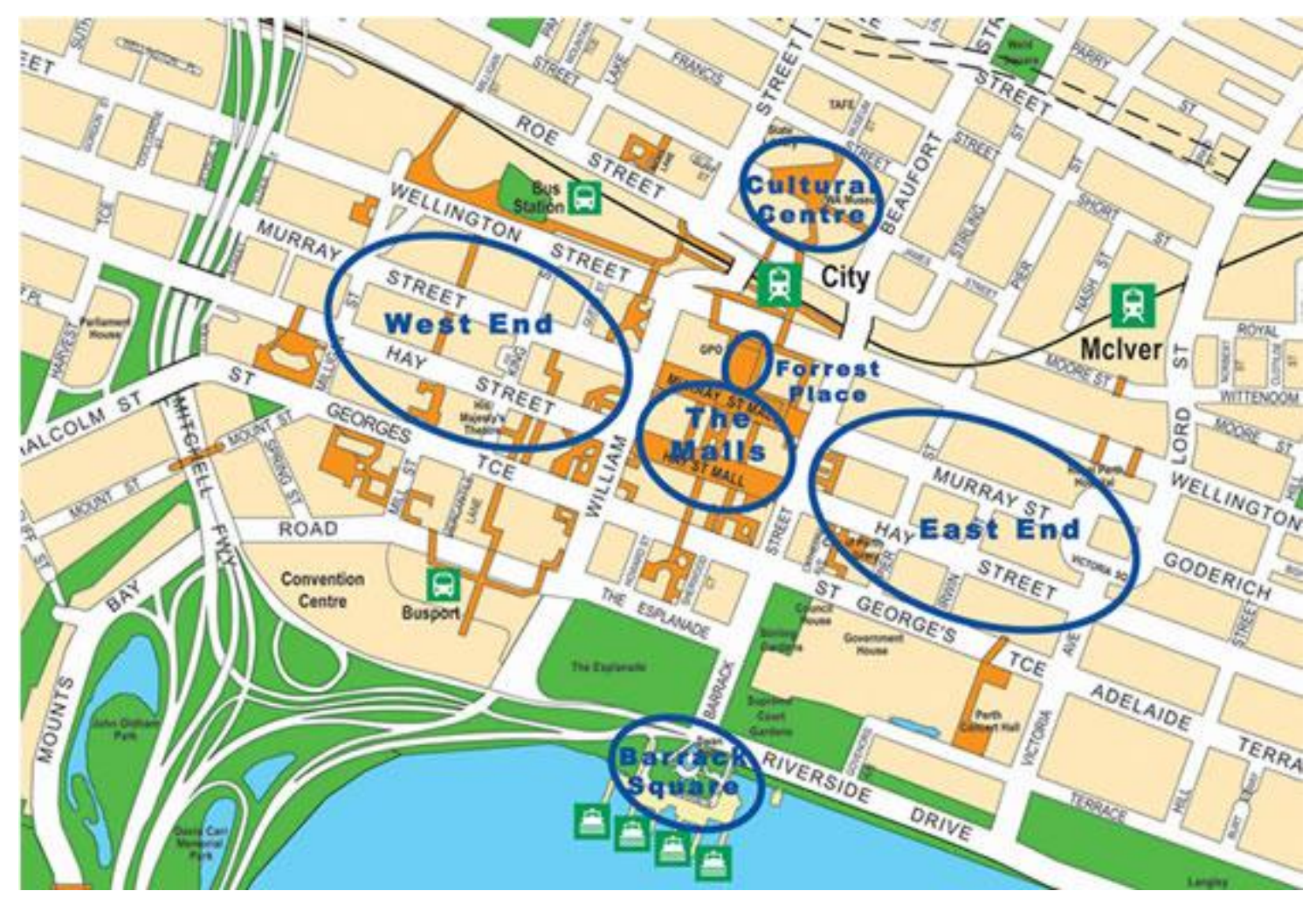

Source: City of Perth 2007 
Figure 5 Summit of Mt Kosciuszko

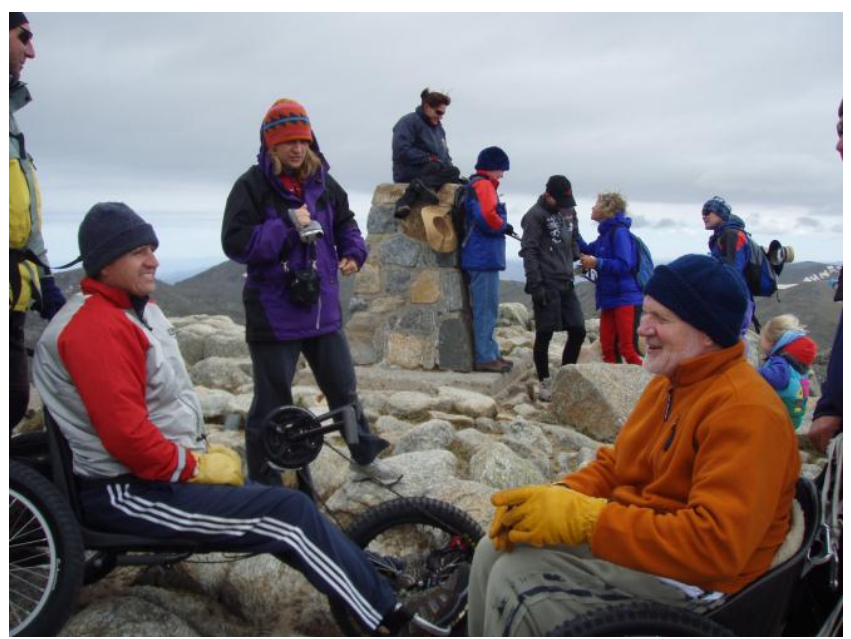

Source: Tracey J. Dickson 


\section{Figure 6: $\quad$ Sydney for All Web Portal Front Page}

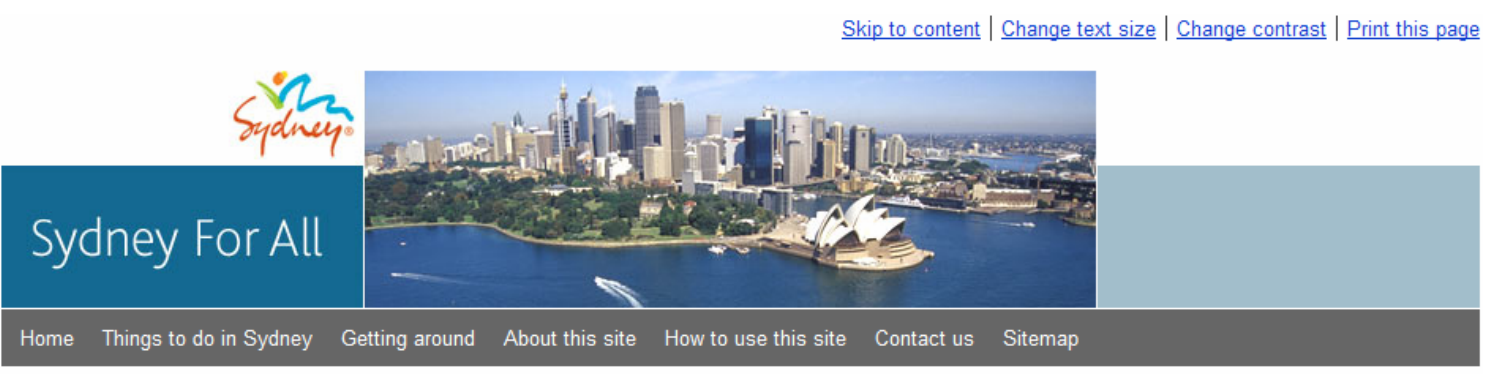

\section{Sydney For All}

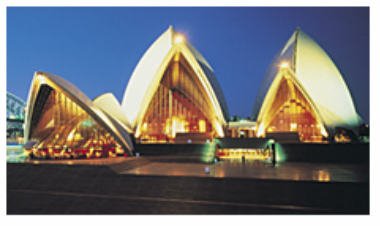

Sydney is an exciting, colourful and vibrant city where it's easy to get out and about. You can tick off all the city's icons - the World Heritage-listed Sydney Opera House, Sydney Harbour and the Sydney Harbour Bridge. You can also discover less well known attractions, all within a short distance of Circular Quay.

There are plenty of attractions that are easy to visit if you have a disability or require assistance with access. Pre-planning your visit will help you enjoy a visit to Sydney at any time of the year.

Things to do in Sydney

Find out the inside story on accessible Sydney experiences around Circular Quay and the harbour. Discover the colonial heritage of The Rocks, be inspired by museums and art galleries, catch a ferry to Manly and enjoy the panoramic views from Sydney Harbour National Park.

\section{Arts and culture}

Enjoy Sydney's vibrant theatres, galleries and performing spaces which offer a range of accessible tours and programs.

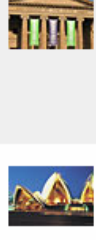
Art Gallery of New South Wales

Explore the Art Gallery of New South Wales and discover a treasure-trove of artistic and culinary excellence framed by magnificent views of Sydney Harbour.

\section{Sydney Opera House}

Visit the Sydney Opera House to see a performance, sip on a cocktail overlooking the harbour or take a backstage

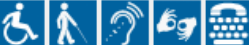

\section{B.}

View more Arts and Culture experiences

\section{Outdoors}

With a near-perfect climate, beautiful gardens and interesting neighbourhoods to explore, you can get a taste of the

\section{How to use this website}

This website is designed to be accessible to everyone. You can adjust the text and colour contrast to suit your needs:

- Change the text size

- Change the contrast

Learn more about how to use this website

Symbols used in this website

Universal icons will help you decide which attractions provide the appropriate level of access.

2 Mobility access is available offering a clear path of travel throughout the venue including an accessible toilet

A A clear path of travel throughout the venue for those who are blind or have low vision

คิ Hearing loop or audio induction loop is available Audio description is available

60 Auslan sign language interpretation is available CC Text captions provided for audio content

Source: http://www.sydneyforall.com/ 